\title{
A variation of colon cut off sign in acute pancreatitis and its mechanism: Double cut-off sign
}

\author{
Nisa Cem Ören, Osman Cancuri, Murat Kocaoğlu, Nail Bulakbașı \\ Department of Radiology, Faculty of Medicine, Near East University, Nicosia, North Cyprus
}

Received: April 25, 2017

Accepted: August 7, 2017

Online Published: August 30, 2017

DOI: $10.5430 /$ ijdi.v5n1p1

URL: https://doi.org/10.5430/ijdi.v5n1p1

\begin{abstract}
The colon cutoff sign is a single air-filled loop of transverse colon with abrupt termination of the distal colon. We report an acute pancreatitis case with colon "double" cut-off sign appears both on abdominal radiograph and computed tomography.
\end{abstract}

Key Words: Signs in imaging, Computed tomography (CT), Colon, Pancreatitis

\section{INTRODUCTION}

The classical colon cutoff sign is a dilated, air-filled transverse colon due extension of the pancreatic inflammation to the phrenicocolic ligament which causes narrowing of the splenic flexure and gasless colon beyond this point. This finding was described on the abdominal X-ray, but a similar sign has also been observed on the CT scanograms. ${ }^{[1,2]}$ This sign was originally described in acute pancreatitis but can also be seen in patients with gastric cancer, ureteric rupture, and abdominal aortic aneurysm rupture presumably secondary to subperitoneal spread of disorders. ${ }^{[1,3]}$ Spreading the peripancreatic inflammation through phrenicocolic ligament is the reason of colon cut-off sign; however, but spreading of the inflammatory exudates through the subperitoneal spaces may cause this sign, as well. We report an acute pancreatitis case whose abdominal radiography and computed tomography (CT) displayed two distended colonic segment- colon "double" cutoff sign-, one at the end of the transverse colon and the second one at the beginning of the descending colon as a result of spreading of peripancreatic inflammation.

\section{CASE REPORT}

A 21-year-old male with a past medical history of acute pancreatitis and hyperlipidemia admitted to the emergency department with the complaints of severe epigastric pain unresponsive to H2-receptor blockers and analgesics. Laboratory test, an abdominal radiograph and CT scan were ordered with the suspicion of acute pancreatitis. Initial laboratory results showed that CRP $20.09 \mathrm{mg} / \mathrm{dl}$ (normal range $0-0.5 \mathrm{mg} / \mathrm{dl}$ ), pancreatic amylase $194 \mathrm{U} / \mathrm{L}$ (normal range 13-53 U/L), lipase $529 \mathrm{U} / \mathrm{L}$ (normal range 13-60 U/L), total cholesterol 1,011 mg/dl (normal range 0-200 mg/dl), and triglyceride $4,646 \mathrm{mg} / \mathrm{dl}$ (normal range $0-150 \mathrm{mg} / \mathrm{dl}$ ). The abdominal radiograph demonstrated two distended colonic loops at the left transverse colon and proximal descending colon and abrupt termination at the end of these gas-filled colonic segments (see Figure 1). An abdominal multidetector CT was obtained following intravenous (iv) contrast media. No oral or rectal contrast media were given. The CT scan was obtained at the arterial and portal venous phase and reconstructed images at different planes were examined. The CT scanograms confirmed the distended two colon loops,

\footnotetext{
*Correspondence: Nisa Cem Ören; Email: cemorenradiologist@gmail.com; Address: Department of Radiology, Faculty of Medicine, Near East University, Nicosia, North Cyprus. 
colon "double" cutoff sign, which was seen on the abdominal radiograph. On the multiplane reformatted CT scans, the pancreas appeared normal in size and homogeneous in density with widespread peripancreatic fat tissue stranding. Peripancreatic inflammatory stranding was extending to the splenic flexure and proximal descending colon with narrowing/spasm of the related colonic sites. CT scans also showed gas-filled and slightly dilated colon segments with abrupt termination (see Figures 2 and 3). Based on the laboratory test results and imaging findings including colon "double" cutoff sign, a diagnosis of acute pancreatitis was made and proper management initiated.

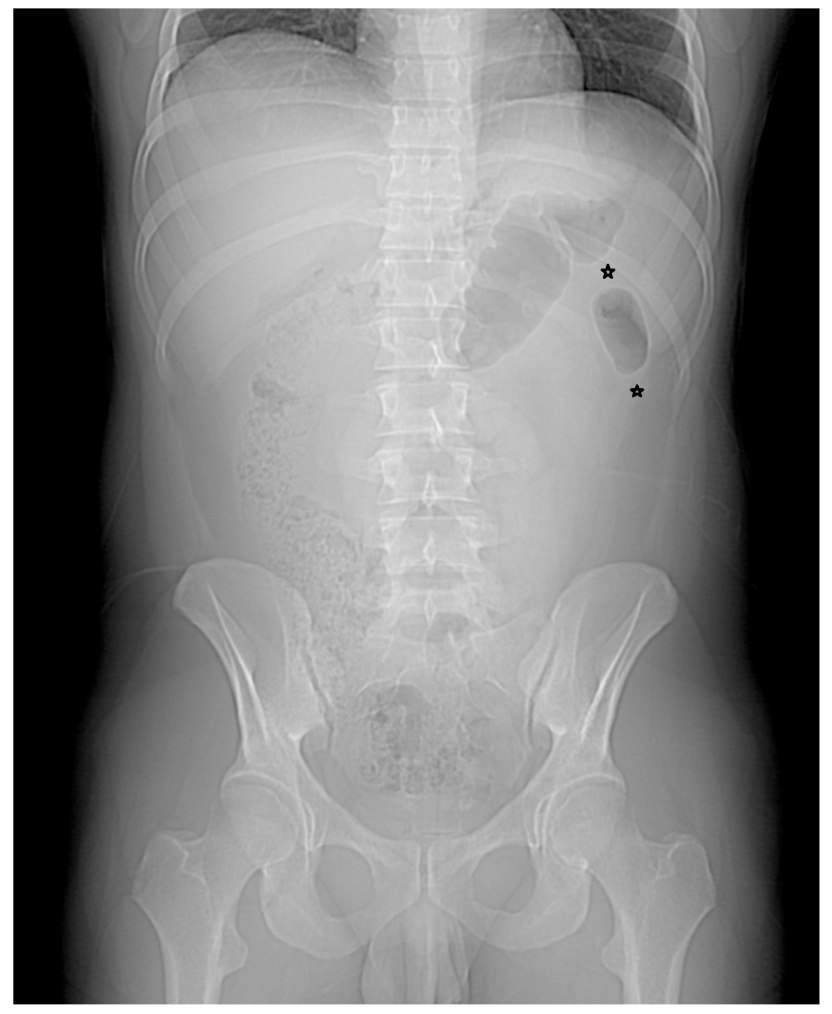

Figure 1. Digital X-Ray of the abdomen demonstrates slightly dilated transverse and proximal descending colon with sudden double terminations of the distal colonic segments (arrows)

\section{Discussion}

Occurrence of colon cut-off sign has been proposed as a result of extension of the peripancreatic inflammatory exudates through the phrenicocolic ligament and narrowing of the colon around the splenic flexure. ${ }^{[1,2]}$ Here we present a variation of colon cut-off sign which two gas-filled colon segments with abrupt terminations secondary to spreading of peripancreatic inflammation through phrenicocolic and subperitoneal space near the descending colon which were resulted narrowing of these colon segments.

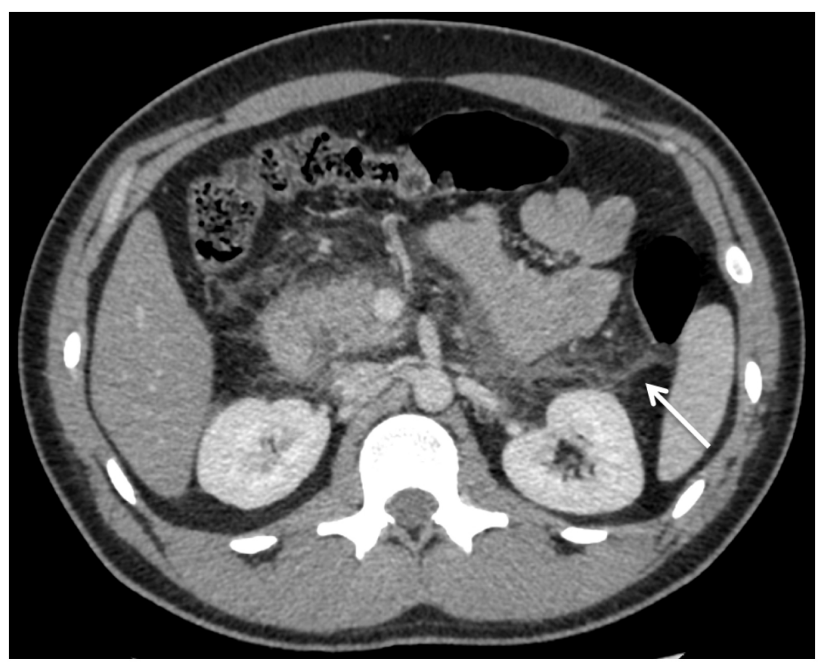

Figure 2. Axial intravenous contrast enhanced CT images of the upper abdomen show the subperitoneal extension of pancreatic exudates to the distended colon loops (white arrows) and abrupt collapse of the distal colon segments creates the second colon cut-off sign

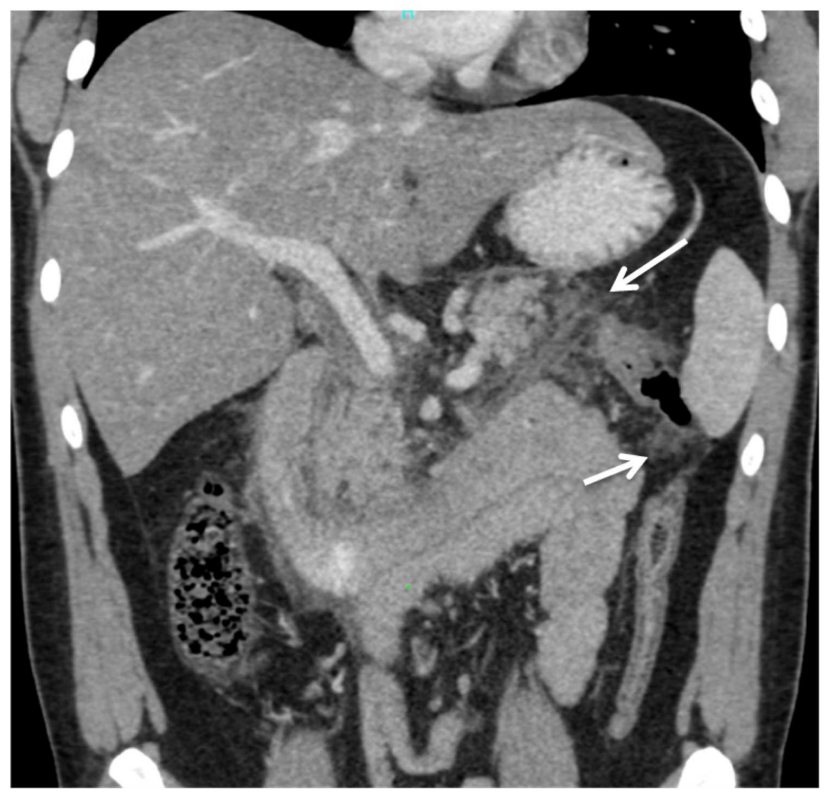

Figure 3. Coronal reformatted contrast enhanced CT image of the abdomen shows the extension of the pancreatic exudates through the phrenicocolic ligament and subperitoneal recess (arrows)

The continuity of the subperitoneal space can explain how the disease spread bidirectionally in the abdomen and pelvis. The subperitoneal space is the area beneath to the serous membrane that outlines the abdominal organs. The anatomic continuity of the subperitoneal space also allows the bidirectional dissemination of the disease between intraperitoneal and extraperitoneal areas and tissues regardless of the mech- 
anism of the spread. ${ }^{[4,5]}$ In our case the peripancreatic exudates reached to the splenic flexure and proximal descending colon through the subperitoneal space, then constricted the related areas and caused the gas-filled distention of the colon proximal to these involved colonic segments.

As in our case, CT is superior to demonstrate the pancreatic changes including whether a necrosis and/or hemorrhage is present or not. In addition, it can show complications including pseudocyst and intraperitoneal abscess formation. MRI may be more helpful in some pathologies, which associating colon in pelvis. ${ }^{[6,7]}$ However, abdominal radiograph is usually the first line imaging method in the setting of acute abdomen. Recognition of abnormal bowel gas pattern helps the radiologist make an accurate diagnosis and allows them to choose proper imaging steps. This case shows that colon cut-off sign can be seen in acute pancreatitis and this may be located lower than classic colon cut-off sign due to spreading of exudates into the descending colon via subperitoneal spaces. So that it should be noted that colon cut-off sign may be located lower than the splenic flexure level on abdominal radiographies. Since CT is more accurate in diagnosing primary disease and its complications, observation of this sign led the clinician to refer the patient for an abdominal CT.

\section{CONFLicts OF INTEREST Disclosure}

The authors have no conflict of interest related to this publication.

\section{REFERENCES}

[1] Indiran V. Colon cutoff sign. Abdom Radiol (NY). 2016; 41(7): 1433-4. https ://doi .org/10.1007/s00261-016-0673-3

[2] Pickhardt PJ. The colon cutoff sign. Radiology. 2000; 215: 387-9. https ://doi.org/10.1148/radiology .215.2.r00ma18387

[3] Liao MT, Chang WC, Tsai SH, et al. The colon cutoff sign: an unusual indicator of urologic disease. Urology. 2008; 71: 1052. PMid:18436281 https ://doi.org/10.1016/j.urology . 2008 .02 .014

[4] Oliphant M, Berne AS, Meyers MA. The subperitoneal space of the abdomen and pelvis: planes of continuity. Am J Roentgenol. 1996; 167: 1433-9. PMid:8956573 https ://doi.org/10.2214/ ajr.167.6.8956573
[5] Brascho DJ, Reynolds TN, Zanca P. The radiographic "Colon Cutoff Sign" in acute pancreatitis. Radiology. 1962; 79: 763-768. PMid:14015002 https ://doi.org/10.1148/79.5.763

[6] Ishikawa K, Hirashita T, Araki K, et al. A case of retroperitoneal mucinous cystadenoma treated successfully by laparoscopic excision. Laparosc Endosc Percutan Tech. 2008; 18(5): 516-9. PMid:18936681 https://doi.org/10.1097/SLE.0b013e318174464c

[7] Isik A, Gursul C, Peker K, et al. Metalloproteinases and Their Inhibitors in Patients with Inguinal Hernia. World J Surg. 2017; 41(5): 1259-1266. PMid:28050662 https ://doi.org/10.1007/ s00268-016-3858-6 